\title{
Assessment of collection samples and kinds of winter rape as to resistance to low temperatures at the level of microgametophyte
}

\author{
M. Kalinova, \\ Dr. of Agricultural Sci., Senior Researcher \\ Institute of Oilseed Crops NAAS
}

The purpose. Assessment of cold resistance of selection material by man gametogophyte, determination of optimum reduced temperature regimen for sprouting blossom dust, selection of coldresistant genotypes with their further use in selection process for creation on their base of kinds and hybrids with high ecological toughness. Methods. Method of sprouting of blossom dust in nutrient medium in conditions of action of the factor. Cold resistance was assessed by ability of blossom dust to germinate and form long pollen tubes. Results. Sprouting of blossom dust in conditions of cold caused decrease of percentage of sprouting and length of pollen tubes in experimental alternatives. Temperature regimens $2 \pm 1$ and $3 \pm 1^{\circ} \mathrm{C}$ have greater selective action in comparison with temperature regimens $5 \pm 1$ and $7 \pm 1^{\circ} \mathrm{C}$ and can be offered as optimum for cold sprouting of blossom dust. Conclusions. It is determined that cold sprouting of blossom dust in nutrient medium in greater extent influenced percentage of germination of blossom dust, than length of pollen tubes. Average extent of lowering by attributes has made accordingly 72,7 and $41,5 \%$. For the further selection researches 3 kinds which have manifested durability to cold to both attributes are offered.

Key words: gametogophyte, pollen tubes, freezing, nutrient medium, extent of lowering.

The purpose of research is to assess the breeding material cold resistance of male gametophyte, the optimal low temperature conditions for germination of pollen, allocation of genotypes resistant to cold, further involving them in the selection process to create on their basis of varieties and hybrids with high ecological plasticity.

For the task used method of pollen germination in nutrient medium in terms of factors. Cold is assessed by the ability of pollen to germinate and form pollen tubes in many research options compared with the control.

Sprouting pollen in cold caused a decrease in the percentage of germination and reduce the length of pollen tubes in the experimental variants. Temperature regimes $2 \pm 1{ }^{\circ} \mathrm{C}$ and $3 \pm 1{ }^{\circ} \mathrm{C}$ discovered a more selective effect compared with $5 \pm 1^{\circ} \mathrm{C}$ and $7 \pm 1{ }^{\circ} \mathrm{C}$ and can be proposed as the optimal temperatures for cold germination of pollen.

Established that cold pollen germination in nutrient medium to a greater extent affected the germination percentage of pollen than the length of pollen tubes, the average rate of decline for these signs was respectively $72.7 \%$ and $41.5 \%$. The analysis identified decline in stable and unstable genotypes. For further breeding research offered three varieties that have expressed resistance to cold on both grounds.

The method of cold germination of pollen can be offered as an accelerated evaluation methods of large collections of rape, allocation of genotypes resistant to cold, creation on their base genotypes bank plastic to be used in breeding programs of environmental direction.

Introduction. Unfavorable conditions of hibernation of winter rape in the Southeast of Ukraine often lead to complete or partial death of crops. One of the main tasks faced by domestic breeders is the creation of varieties and hybrids of winter rape resistant to local cultivation conditions. One of the first conditions for solving the problem is to explore the potential of the gene pool in order to detect and attract 
heat-resistant genotypes from it, and the creation on their basis of varieties and hybrids resistant to temperature factors.

Conducting an estimation of adaptive possibilities of the gene pool on the basis of the application of the most effective methods of diagnostics of resistance allows to analyze in a short period of a large number of genotypes under the resistance to the action of extreme temperatures.

Currently, for the determination of temperature-resistant genotypes, the method of evaluation for male gametophytes is used, which allows a mass estimation of the gene pool in a short period of time [15]. The method of estimation by the male gametophyte has been worked out on many crops and, from the conditions of the creation of the temperature background, can be carried out in two directions: preliminary treatment of pollen with stress temperatures and further germination thereof in the nutrient medium or germination of pollen in the nutrient medium against the background of the action of the selective factor [6-11].

The time and temperature modes of pollen germination in the nutrient medium in the low temperature were selected, the influence of this factor on certain pollen quality was studied, and the evaluation of the resistance to the lower temperatures by the male gamitophyte of 34 sorts and winter rape varieties was given.

The purpose of the research is to evaluate the cold resistance of the breeding material on the male gametophyte and to allocate stable genotypes for their further involvement in the breeding process and the creation on their base of cold resistant varieties and hybrids with high ecological plasticity.

To evaluate the cold resistance of the samples, the method of germination in the nutrient medium of the pollen was used under the conditions of the factor. Several temperature regimes have been selected in order to obtain more objective data regarding the precise differentiation of samples on this basis. The pollen was collected in the morning from 30-35 flowers of the same sample, carefully mixed and a small amount of it was stirred in 2-3 drops of the nutrient medium [12] on a slide glass, which was placed on softened filter paper in a Petri dish. Further, the experimental variants were placed in a refrigerating chamber and sprouted for $24 \pm 1$ hours at low positive temperature. The control variant pollen was sprouted for 2 hours in a thermostat at a temperature of $24 \pm 1 \stackrel{\circ}{\circ}$.

The cold resistance of the sample was determined by the degree of reduction in the percentage of germination of pollen and the length of pollen tubes in experimental variants compared with the control ones. The degree of reduction of indicators was determined by the formula:

$$
\mathrm{X}=(\mathrm{K}-\mathrm{O}) / \mathrm{K} \times 100 \%
$$

where $\mathrm{K}$ - percentage of germination, length of pollen tubes in control; Oh - the percentage of germination, the length of pollen tubes in the experiment. Experiments were carried out in 3 replicates. Statistical processing of the results was carried out according to generally accepted methods with the help of applied programs at the PWEP.

Research results. As a result of the studies, the influence of the lowered temperatures on the germination of the pollen and the length of the pollen tubes was determined. According to the experiment in the experimental variants, all the selected temperature regimes led to a decrease in the analyzed parameters. Temperature regimes $5 \pm 1 \stackrel{\circ}{\circ} \mathrm{C}$ and $7 \pm 1 \stackrel{\circ}{\circ} \mathrm{C}$ have less rigid influence on germination of pollen (Table 1). The maximum degree of reduction on this basis amounted to $84.3 \%$ for the Optima variety, the minimum $-27.0 \%$ for the Senate variety. The degree of reduction of germination of pollen in the mail half of varieties in this case was not higher than $50 \%$, and the average for all grades $-56.2 \%$. With the application of lower temperatures $2 \pm 1^{\circ} \mathrm{C}$ and $3 \pm 1^{\circ} \mathrm{C}$, this indicator increased in all samples analyzed. Two thirds of them had a degree of reduction of more than $80 \%$, the maximum of which was $99.5 \%$ - the Kata variety. With the exception of the Solo variety, which had a minimum degree of germination of pollen $-30.5 \%$, in other samples, the indicator was higher than $50 \%$, and the average for all grades $-80.3 \%$. It should be noted that the degree of decline on this basis had a significant level of significance in the application of all temperature regimes and in all samples. 
Table 1. Influence of prolonged germination in a nutrient medium under conditions of reduced temperature on sprout of winter rape, $\%$

\begin{tabular}{|c|c|c|c|c|c|}
\hline \multirow{2}{*}{$\begin{array}{l}\text { № } \\
p / p\end{array}$} & \multirow{2}{*}{$\begin{array}{l}\text { Name of the variety / } \\
\text { varietal specimen }\end{array}$} & \multirow{2}{*}{$\begin{array}{l}\text { Germination } \\
\text { temperature }\end{array}$} & \multicolumn{3}{|c|}{ Germination of pollen } \\
\hline & & & Control & Experience & Degree of decline \\
\hline 1 & Cornet & \multirow{3}{*}{$7 \pm 1^{\circ} \mathrm{C}$} & 28,7 & 10,0 & $64,1^{* *}$ \\
\hline 2 & Champion & & 54,6 & 10,9 & $79,3^{* * *}$ \\
\hline 3 & Optima & & 40,0 & 6,1 & $84,3^{\star \star *}$ \\
\hline 4 & $\mathrm{~F} 32$ & \multirow{14}{*}{$5 \pm 1^{\circ} \mathrm{C}$} & 46,0 & 6,3 & $84,0^{\star \star \star}$ \\
\hline 5 & Panther & & 40,1 & 11,9 & $70,3^{\star \star \star}$ \\
\hline 6 & Tenor & & 58,2 & 24,6 & $57,2^{*}$ \\
\hline 7 & Cheremosh & & 73,9 & 35,7 & $52,0^{*}$ \\
\hline 8 & Antaria & & 38,1 & 19,9 & $42,1^{*}$ \\
\hline 9 & Senator & & 43,6 & 32,2 & $27,0^{*}$ \\
\hline 10 & Steluza & & 73,2 & 15,7 & $78,6^{\star \star \star}$ \\
\hline 11 & Solo & & 42,0 & 28,8 & $29,4^{*}$ \\
\hline 12 & Anna & & 60,4 & 39,6 & $34,1^{*}$ \\
\hline 13 & Atlant & & 56,9 & 24,43 & $54,9^{*}$ \\
\hline 14 & Champion & & 71,9 & 26,6 & $63,0^{* *}$ \\
\hline 15 & Harnes & & 59,4 & 30,9 & $48,3^{*}$ \\
\hline 16 & Legion & & 77,6 & 49,8 & $36,7^{\star \star}$ \\
\hline 17 & Loris & & 80,6 & 39,9 & $50,5^{*}$ \\
\hline 18 & Solo & \multirow{26}{*}{$3 \pm 1 \stackrel{\circ}{C}$} & 62,5 & 43,1 & $30,5^{*}$ \\
\hline 19 & Steluza & & 68,7 & 24,2 & $65,1^{* *}$ \\
\hline 20 & Atlant & & 69,7 & 22,3 & $68,0^{* \star}$ \\
\hline 21 & Anna & & 68,3 & 33,1 & $51,3^{*}$ \\
\hline 22 & 33 & & 65,4 & 3,4 & $94,7^{\star \star \star}$ \\
\hline 23 & 35 & & 63,5 & 5,9 & $90,6^{\star * \star}$ \\
\hline 24 & 36 & & 56,2 & 1,6 & $97,0^{\star \star \star}$ \\
\hline 25 & Senator & & 55,9 & 5,2 & $90,6^{\star * *}$ \\
\hline 26 & Vectra & & 44,1 & 3,3 & $92,5^{\star * \star}$ \\
\hline 27 & Dema & & 68,2 & 3,6 & $94,7^{\star \star \star}$ \\
\hline 28 & ДР-13H & & 62,6 & 10,0 & $84,0^{\star \star \star}$ \\
\hline 29 & Djesper & & 46,3 & 7,0 & $84,9^{\star \star \star}$ \\
\hline 30 & RPC-2031 & & 37,9 & 4,9 & $86,7^{\star \star \star}$ \\
\hline 31 & Black velvet & & 58,0 & 5,0 & $91,5^{\star \star \star}$ \\
\hline 32 & $\mathrm{H}-450$ & & 61,1 & 4,9 & $92,1^{* * *}$ \\
\hline 33 & K-571 & & 61,2 & 3,7 & $94,0^{* \star *}$ \\
\hline 34 & Milena & & 47,5 & 14,7 & $69,4^{* *}$ \\
\hline 35 & RPC-2031 & & 41,1 & 14,3 & $65,8^{* *}$ \\
\hline 36 & RPC-2031 & & 51,5 & 1,4 & $97,0^{\star * *}$ \\
\hline 37 & NS-O-6 & & 40,5 & 7,6 & $81,8^{\star \star \star}$ \\
\hline 38 & NS-O-14 & & 53,3 & 11,6 & $78,1^{\star \star \star}$ \\
\hline 39 & NS-O-20 & & 55,8 & 13,1 & $76,4^{\star \star \star}$ \\
\hline 40 & NS-O-2 & & 44,8 & 10,7 & $76,5^{\star \star \star}$ \\
\hline 41 & Kata & & 42,0 & 0,3 & $99,5^{\star \star \star}$ \\
\hline 42 & Mira & & 71,4 & 27,9 & $60,6^{\star *}$ \\
\hline 43 & Galicky & & 46,9 & 6,9 & $86,3^{* * *}$ \\
\hline
\end{tabular}




\begin{tabular}{|c|c|c|c|c|c|}
\hline 44 & Loris & & 66,0 & 24,6 & $58,9^{*}$ \\
\hline 45 & Atlant & & 70,7 & 21,4 & $70,1^{* *}$ \\
\hline 46 & Loris & \multirow{9}{*}{$2 \pm 1^{\circ} \mathrm{C}$} & 68,1 & 10,7 & $84,1^{\star \star \star}$ \\
\hline 47 & Solo & & 59,0 & 12,7 & $78,4^{\star \star \star}$ \\
\hline 48 & Anna & & 64,6 & 30,3 & $51,2^{*}$ \\
\hline 49 & Steluza & & 67,4 & 33,0 & $51,9^{*}$ \\
\hline 50 & Rokhan & & 74,0 & 1,6 & $97,7^{* * *}$ \\
\hline 51 & Chelsi & & 31,5 & 0,7 & $97,9^{\star \star \star}$ \\
\hline 52 & Panther & & 64,0 & 3,8 & $93,7^{\star \star \star}$ \\
\hline 53 & Lirajet & & 67,8 & 5,1 & $92,3^{\star * \star}$ \\
\hline 54 & Expres & & 60,3 & 4,1 & $97,3^{* * *}$ \\
\hline
\end{tabular}

On the basis of the length of the pollen tubes (Table 2) under conditions of higher temperatures of $5 \pm$ $1 \stackrel{\circ}{\circ}$ and $7 \pm 1 \stackrel{\circ}{\circ}$ the degree of decline in the test in experimental variants ranged from negative indicators $-3.1 \%$ and $-8.2 \%$ (Cornet and Tenor ) to $47 \%$ (Champion). In all samples, the indicator in this case was below $50 \%$, and the average in grades was $26.6 \%$. When applying a tougher background $2 \pm 1$ ${ }^{\circ} \mathrm{C}$ and $3 \pm 1{ }^{\circ} \mathrm{C}$ in the group of analyzed samples, the difference between the control and trial variants increased. The maximum degree of reduction was $83.1 \%$ (Kata), the minimum - $23.9 \%$ (Stylutza), and the average in grades $-48.3 \%$. Thus, the average indicator, from the conditions of use of lower temperatures, increased almost 2 times. It should be noted that the significance level was significant in almost all samples. If we compare the average data from both indicators, then at application of $5 \pm 1 \stackrel{\circ}{\circ} \mathrm{C}$ and $7 \pm 1$ ${ }^{\circ} \mathrm{C}$ on the first indicator it made $56,2 \%$, on the second $-26,6 \%$, at application $2 \pm 1^{\circ} \mathrm{C}$ and $3 \pm 1{ }^{\circ} \mathrm{C}$, respectively, $80,3 \%$ and $48.3 \%$. The average indices for reducing the germination of pollen and the length of pollen tubes in the experiment in all temperature regimes were respectively $72.7 \%$ and $41.5 \%$. In this way, the cold germination of pollen in the nutrient medium to a greater extent affected the percentage of germination of the pollen than the length of the pollen tubes.

Table 2. Influence of prolonged germination of the winter rapeseed pollen in a nutrient medium under reduced temperature on the length of pollen tubes

\begin{tabular}{|c|c|c|c|c|c|}
\hline \multirow{2}{*}{$\begin{array}{l}\text { № } \\
\mathrm{p} / \mathrm{p}\end{array}$} & \multirow{2}{*}{$\begin{array}{l}\text { Name of the variety / } \\
\text { varietal specimen }\end{array}$} & \multirow[b]{2}{*}{$\begin{array}{l}\text { Germination } \\
\text { temperature }\end{array}$} & \multicolumn{3}{|c|}{ Length of pollen tube ${ }^{1}$} \\
\hline & & & Control & Experience & $\begin{array}{l}\text { Degree of } \\
\text { decline }\end{array}$ \\
\hline 1 & Cornet & \multirow{3}{*}{$7 \pm 1^{\circ} \mathrm{C}$} & $9,3 \pm 0,49$ & $9,5 \pm 0,86$ & $-3,1$ \\
\hline 2 & Champion & & $15,1 \pm 0,98$ & $7,5 \pm 0,53$ & $47,0^{\star *}$ \\
\hline 3 & Optima & & $10,8 \pm 0,49$ & $6,7 \pm 0,44$ & $37,6^{*}$ \\
\hline 4 & $\mathrm{~F} / 32$ & \multirow{14}{*}{$5 \pm 1^{\circ} \mathrm{C}$} & $15,6 \pm 2,19$ & $12,2 \pm 3,18$ & 23,0 \\
\hline 5 & Panther & & $11,4 \pm 1,35$ & $6,3 \pm 0,58$ & $41,5^{*}$ \\
\hline 6 & Tenor & & $8,5 \pm 0,67$ & $9,1 \pm 0,74$ & $-8,2$ \\
\hline 7 & Cheremosh & & $12,1 \pm 1,65$ & $7,6 \pm 0,41$ & $35,0^{*}$ \\
\hline 8 & Antaria & & $8,6 \pm 0,42$ & $7,2 \pm 0,42$ & 15,4 \\
\hline 9 & Senator & & $8,7 \pm 0,30$ & $7,4 \pm 0,34$ & 14,4 \\
\hline 10 & Steluza & & $12,7 \pm 0,61$ & $8,9 \pm 0,44$ & $30,2^{*}$ \\
\hline 11 & Solo & & $11,4 \pm 0,41$ & $9,2 \pm 0,45$ & 19,9 \\
\hline 12 & Anna & & $11,1 \pm 0,65$ & $9,8 \pm 0,55$ & 9,6 \\
\hline 13 & Atlant & & $16,6 \pm 0,96$ & $9,2 \pm 0,37$ & $43,4^{\star \star}$ \\
\hline 14 & Champion & & $10,6 \pm 0,47$ & $7,2 \pm 0,32$ & $31,6^{\star \star}$ \\
\hline 15 & Harnes & & $11,7 \pm 0,66$ & $6,6 \pm 0,31$ & $43,2^{\star *}$ \\
\hline 16 & Legion & & $12,6 \pm 0,68$ & $7,1 \pm 0,39$ & $43,3^{\star *}$ \\
\hline 17 & Loris & & $10,0 \pm 0,53$ & $7,1 \pm 0,33$ & $27,7^{*}$ \\
\hline
\end{tabular}




\begin{tabular}{|c|c|c|c|c|c|}
\hline 18 & Solo & \multirow{14}{*}{$3 \pm 1^{\circ} \mathrm{C}$} & $9,2 \pm 0,30$ & $6,3 \pm 0,38$ & $31,5^{*}$ \\
\hline 19 & \begin{tabular}{|l|} 
Steluza \\
\end{tabular} & & $10,4 \pm 0,47$ & $7,8 \pm 0,48$ & $23,9^{*}$ \\
\hline 20 & Atlant & & $11,7 \pm 0,42$ & $8,0 \pm 0,38$ & $31,1^{*}$ \\
\hline 21 & Anna & & $10,5 \pm 0,27$ & $5,8 \pm 0,28$ & $43,1^{*}$ \\
\hline 22 & 33 & & $10.3 \pm 0,39$ & $5,6 \pm 0,29$ & $45,4^{*}$ \\
\hline 23 & 35 & & $8,2 \pm 0,37$ & $5,6 \pm 0,37$ & $31,4^{*}$ \\
\hline 24 & 36 & & $13,9 \pm 0,50$ & $5,1 \pm 0,36$ & $60,5^{\star \star *}$ \\
\hline 25 & Senator & & $12,5 \pm 0,59$ & $6,6 \pm 0,44$ & $47,3^{\star *}$ \\
\hline 26 & Vectra & & $13,5 \pm 0,58$ & $5,3 \pm 0,35$ & $60,3^{* \star *}$ \\
\hline 27 & Dema & & $9,0 \pm 0,45$ & $4,7 \pm 0,28$ & $47,0^{\star \star *}$ \\
\hline 28 & ДР-13H & & $8,1 \pm 0,41$ & $5,6 \pm 0,31$ & $31,0^{* * *}$ \\
\hline 29 & Djesper & & $7,6 \pm 0,42$ & $5,6 \pm 0,30$ & $27.1^{*}$ \\
\hline 30 & RPC-2031 & & $8,3 \pm 0,48$ & $5,0 \pm 0,25$ & $40,4^{* \star *}$ \\
\hline 31 & \begin{tabular}{|l} 
Black velvet \\
\end{tabular} & & $9,6 \pm 0,43$ & $4,8 \pm 0,30$ & $49,8^{* * *}$ \\
\hline 32 & $\mathrm{H}-450$ & \multirow{13}{*}{$3 \pm 1^{\circ} \mathrm{C}$} & $9,6 \pm 0,54$ & $4,7 \pm 0,27$ & $51,4^{\star \star *}$ \\
\hline 33 & K-571 & & $9,1 \pm 0,44$ & $4,3 \pm 0,19$ & $52,7^{* \star *}$ \\
\hline 34 & \begin{tabular}{|l} 
Milena \\
\end{tabular} & & $10,9 \pm 0,55$ & $4,7 \pm 0,22$ & $56,5^{\star \star *}$ \\
\hline 35 & RPC-2031 & & $9,5 \pm 0,48$ & $5,3 \pm 0,23$ & $44,4^{\star \star *}$ \\
\hline 36 & RPC-2031 & & $13,1 \pm 0,63$ & $5,2 \pm 1,0$ & $60,0^{\star * *}$ \\
\hline 37 & NS-O-6 & & $7,4 \pm 0,30$ & $4,4 \pm 0,22$ & $40,0^{\star \star *}$ \\
\hline 38 & NS-O-14 & & $8,1 \pm 0,33$ & $4,4 \pm 0,18$ & $46,1^{* \star *}$ \\
\hline 39 & NS-O-20 & & $11,6 \pm 0,33$ & $4,3 \pm 0,14$ & $62,5^{\star \star *}$ \\
\hline 40 & NS-O-2 & & $7,1 \pm 0,28$ & $3,8 \pm 0,1$ & $46,5^{\star \star \star}$ \\
\hline 41 & Kata & & $6,3 \pm 0,23$ & $1,2 \pm 0,32$ & $83,1^{\star \star *}$ \\
\hline 42 & Mira & & $9,6 \pm 0,46$ & $4,6 \pm 0,20$ & $52,0^{\star * *}$ \\
\hline 43 & Galicky & & $8,3 \pm 0,39$ & $3,4 \pm 0,11$ & $58,8^{\star * *}$ \\
\hline 44 & Loris & & $10,5 \pm 0,30$ & $5,7 \pm 0,25$ & $45,1^{* \star *}$ \\
\hline 45 & Atlant & \multirow{10}{*}{$2 \pm 1^{\circ} \mathrm{C}$} & $11,6 \pm 0,71$ & $6,2 \pm 0,29$ & $46,7^{\star \star *}$ \\
\hline 46 & Loris & & $13,4 \pm 0,70$ & $6,9 \pm 0,38$ & $48,3^{\star \star *}$ \\
\hline 47 & \begin{tabular}{|l|} 
Solo \\
\end{tabular} & & $9,7 \pm 0,67$ & $5,8 \pm 0,53$ & $39,5^{\star \star \star}$ \\
\hline 48 & Anna & & $10.6 \pm 0,62$ & $4,6 \pm 0,41$ & $55,5^{\star \star \star}$ \\
\hline 49 & \begin{tabular}{|l} 
Steluza \\
\end{tabular} & & $10.5 \pm 0,99$ & $7,5 \pm 0,42$ & $29,2^{*}$ \\
\hline 50 & Rokhan & & $11,7 \pm 0,60$ & $5,0 \pm 0,51$ & $57,2^{\star \star \star}$ \\
\hline 51 & \begin{tabular}{|l} 
Chelsi \\
\end{tabular} & & $13,7 \pm 0,49$ & $4,7 \pm 0,43$ & $65,3^{\star * *}$ \\
\hline 52 & Panther & & $11,1 \pm 0,74$ & $4,6 \pm 0,45$ & $56,8^{\star \star *}$ \\
\hline 53 & Lirajet & & $14,7 \pm 0,92$ & $4,2 \pm 0.19$ & $71,4^{\star * *}$ \\
\hline 54 & Expres & & $8,2 \pm 0,44$ & $4,2 \pm 0,75$ & $48,8^{\star * *}$ \\
\hline
\end{tabular}

${ }^{*},{ }^{* *},{ }^{* * *}$ - the difference is significant at $p \leq 0,01,0.05$ and 0.001 , respectively

1-length of pollen tubes is indicated in microscope eyepiece-micrometer divisions

All analyzed varieties and sorts were identified as stable and unstable according to the degree of decline in the experimental variants. These genotypes have respectively the maximum low or high values of the lowering stage. But a group of unconditionally stable samples and varieties that had a low degree of decline on both signs were included at the same time Senator, Solo and Anna. Varieties and sorted specimens with the highest degree of decline on both signs were classified as unstable, respectively, Vectra, Kata, Lirajet, Chelsea and 36, RPC-2031. All other varieties, depending on the temperature of the treatment of pollen, showed a different degree of resistance to cold on the grounds.

\section{Conclusions}

Germination of pollen under cold conditions caused a decrease in the percentage of germination and the length of pollen tubes in experimental variants compared with cathodic. The degree of reduction of the 
indices in the experimental variants with the application of all temperature regimes was significant in almost all analyzed samples. Temperature regimes of $2 \pm 1{ }^{\circ} \mathrm{C}$ and $3 \pm 1 \stackrel{\circ}{\circ} \mathrm{C}$ have a more selective effect compared to $5 \pm 1{ }^{\circ} \mathrm{C}$ and $7 \pm 1 \stackrel{\circ}{\circ} \mathrm{C}$. Cold sprouting of the pollen in the nutrient medium to a greater extent affected the percentage of germination of the pollen than the length of the pollen tubes. The different reaction to low temperature of microhametophyte of studied genotypes of winter rape allowed to differentiate them from resistance to cold on stable and unstable. For further breeding studies in order to create cold resistant varieties and hybrids, we presented 3 varieties Solo, Anna and Senator, which by degree of reduction on both of the analyzed features have shown resistances to the cold factor.

\section{References}

1. Anton LP Estimation of resistance of tomato pollen to temperature and osmotic stress // Proceedings of the International Scientific Conference "Plant Physiology - The Theoretical Foundations of Innovative Agro-and Phytobiotechnologies" Published by the Federal State University of Agriculture and Higher Education of the Russian Academy of Sciences "Kaliningrad", Kyiv, 04-II, pp. 43-45.

2. Lyakh VA, Soroka A.I. Pollen selection as a way to intensify the selection of oilseeds // Scientific and Technical Bulletin of the Institute of Oilseeds of NAAS. - 2014. - Vip. 20. - P.72-80.

3. Dosina E.S., Anokhin V.S. Characteristics of collection samples and intersort hybrids of vegetable beans on resistance to lowered temperatures // Genetics and biotechnology of the XXI century. Fundamental and Applied Aspects: Materials International scientific conf. Dec. 3-6 2008-Minsk: Izd. center of BSU. Pp. 76-78

4. Kravchenko AN, Klimenko O.A. Physiological and genetic approaches for assessing the resistance of corn to stressed lower temperatures. // All-Russian Symposium "Ecology of Megacities: Fundamental Foundations and Innovative Technologies" and the School of Young Scientists on Environmental Physiology of Plants. -M .: Publishing House "Forest Country" 2011. - p.81

5. Aspects of rational nature management in the Brest region / Michalchuk N.V., Galutz O.A., Kovalev IV [and other]. - Minsk: Belarus. sound 2013 - 259s.

6. Nikolayev AV, Golyshkina L.V. Environmental assessment of black currant varieties according to characteristics of pollen grains // Actual problems of horticulture of Russia and ways of their solution. National All-Russia Research Institute of Fruit Selection. Sat articles conf. 2007 -392s.

7. Saltanovich T.I. Diagnosis of stability of intraspecific hybrid tomatoes on the basis of male gametophytes // Materials of the International. scientific Conf «Plant Physiology - the Theoretical Basis of Innovative Agro-and Phytobiotechnologies» Publishing of the FGBOOU VPO «KSTU» Kaliningrad, 2014, p. II, pp. 391-393.

8. Kulikov Yu.A., Daniluk GP, Kulikova N.N. Creation of the source material of sweet pepper by the method of gametophyte selection // Agrobiology Belaya Tserkov Belotserkovsky National Agrarian University - 2014. - No. 2 pp. 97-100

9. Totsky I.V., Lyakh V.A. Methods of gametophytic selection for drought tolerance in sunflower of a cultural // Scientific and technical bulletin of the Institute of Oilseeds of NAAS. - 2015. - Issue 22. P. 43-51.

10. Kilchevsky AV, Pugacheva I.G. Hamlet selection of tomatoes for cold resistance // Weight. National Acad Nawuk Belarus. Sir Agrar Nudity - 2002. - No. 4. - P. 35-39.

11. Lyakh V.A., Soroka A.I., Kalinova M.G. Pollen storage at low temperature as a procedure for the improvement of cold tolerance in spring rape, Brassica napus L., // Plant Breeding.-1998.-Vol.117.-P.389391.

12 Methods of selection of valuable genotypes at the level of pollen // V. Lyakh [and others]. Zaporozhye 2000. Institute of Oil Cultures. Method. recommendations s - 9 